break the damaging reign of the car, mixed-use neighbourhoods with greater diversity, and more investment in public transport. China has long been said to have 'a thousand cities with the same face'. Now it is trying to put a smile on them.

Amid the scientific and social priorities for the coming years, the study and design of cities must be right at the top. Humans are now an urban species and have been since city dwellers started to outnumber rural folk for the first time almost a decade ago. The trend is set to continue, and the United Nations has estimated that $70 \%$ of the global population will live in an urban environment by 2050 .

What kind of environment will that be? The signs so far are not good. Too many people, especially those in rapidly developing (and urbanizing) countries experience city life much as Charles Dickens put it in his 1850s work Little Dorrit: "Miles of close wells and pits of houses, where the inhabitants gasped for air, stretched far away towards every point of the compass. Through the heart of the town a deadly sewer ebbed and flowed, in the place of a fine fresh river."

Scientists are responding. Universities in many of the world's cities - London, New York, Boston, Madrid, Glasgow, Zurich and Singapore among them - are leading a new wave of evidence-driven, data-rich research that aims to understand what makes cities tick, and to keep them running smoothly. Some of these issues, from how best city dwellers should move around, to how to protect their water and them from it, are discussed in a collection of articles this week in a Nature Outlook supplement on urban health and well-being (turn to page 306).

Science and technology has a chequered history in the city. On the plus side, great urban visionaries of the past - such as the British town planner Patrick Geddes - trained as scientists, and were able to bring the ideas of ecology and the natural environment to their social

tasks. In a less enlightened contribution, some of the haste to design cities around the automobile was justified by claims to rational science. (Even today, many cities in the developing world spend $70 \%$ of their transport budgets on serving the car, even though $70 \%$ of trips are made by foot or public transport.)

By the 1960s, cities were almost a frontier too far even for science. Asked by then-US President Lyndon Johnson to solve the social prob-

"Urban science has some way to go to restore its reputation." lems rooted in US urban areas, a specially convened group of scientists in Woods Hole in Massachusetts responded that "creating a safe, happy city is a greater challenge than a trip to the moon". Residents of the Bronx in New York City would have agreed: a botched attempt to model demand for fire services in the 1970s contributed to a series of ill-judged fire-station closures and an outbreak of (oddly, not predicted) fires.

Urban science has some way to go to restore its reputation, but the era of big data offers an opportunity, and a new way of thinking. Even as civic leaders crow about the unique merits of their towns, research on cities is trying to dismantle them. Rather than looking at what makes cities different - and then planning accordingly — modern urban science seeks what they have in common.

The new models of urban life start from the ground up and track, for example, people's journeys and the reasons for them, rather than the flow of traffic through a specific, frequently gridlocked roundabout or intersection. They try to make city science quantifiable, testable and reproducible. It's a big ask - but that trip to the Moon was achieved. And as the same Woods Hole scientists also told Johnson, the problems of the city "nevertheless, can be attacked in the same logical way we have gone about exploring the universe".

\section{Practical DNA}

\section{The promise of DNA origami shows signs of coming to fruition a decade after its debut.}

S cience seeks to understand the mechanisms of nature, to develop tools of investigation and to make useful and sometimes revolutionary things with which to build our future. And every now and again, a piece of science comes along that seems like a work of art.

All of this was exemplified by a research paper published in Nature ten years ago that, literally, produced smiles (see Nature 440, 297$302 ; 2006)$. Using an astoundingly simple and general method to assemble strands of DNA into arbitrary shapes, the research generated 'smileys' that graced the cover of Nature and announced the arrival of DNA origami to the world.

The robustness of this method changed the game for DNA nanotechnology, which has since developed at an astonishing pace. It is a beautiful demonstration of how science can progress.

The concept behind DNA origami was laid down in the early 1980 s by crystallographer Nadrian Seeman, who realized that the ability of DNA molecules to carry and transfer information according to strict base-pairing rules could be used to rationally assemble structures with precisely controlled nanoscale features.

This unprecedented level of programmability makes DNA a unique building material. Nanodesigners have embraced the biomolecule to fabricate intricate tiled patterns, boxes with lids that can be opened and arrays of precisely located binding elements that can incorporate proteins, dyes and other functional materials into regular lattices.

Pivotal to the success of DNA as a nanoscale building material have been automated methods to synthesize short DNA molecules

of any sequence. A detailed understanding of how base-pairing translates into the formation of DNA double helices has also been crucial. Such helices control the shapes into which DNA molecules with given sequences will fold.

DNA origami provides the missing ingredient: a versatile yet straightforward assembly method. Computer-aided design programs determine how DNA scaffolds can be folded to realize desired structures, as well as which short DNA strands, or staples, are needed to hold the structures in shape.

Individual structures can also be assembled into more complex patterns, and sites that bind to functional materials can be introduced at any position.

The many eye-catching structures that have been built have pleased those of us with an appreciation of beauty. But even the most creative science will ultimately face the question: what is the point?

DNA nanotechnology has long searched for relevance. It is unrivalled in its ability to build complex structures with near-atomic precision, but the results tend to be labile, soft and so small that it is a challenge to put them to practical use.

Yet applications that address basic problems in science have emerged. DNA structures can serve as tools for determining the structures of proteins or as templates for assembling electronic components and basic devices. Responsive DNA structures can target diseased cells, and artificial membrane channels formed from DNA can act as single-molecule sensors.

Real-world applications might become feasible through recent developments - for example, improvements to the folding process that reduce assembly time and boost yield. Initial steps have also been taken to efficiently pair DNA nanostructures with technologi-

$D$ NATURE.COM To comment online, click on Editorials at: go.nature.com/xhunqv cally relevant substrates.

Many challenges remain, and DNA nanotechnology is far from maturity. But a growing number of scientists are entering the field to make more than just art. Watch this space. 